\title{
Does the $\mathrm{CO}_{2}$ laser reduce bond strength in different types of ceramic brackets?
}

\author{
Fábio Lourenço Romano1, Giovanna Pessoti², Rodrigo Galo3, Jaciara Miranda Gomes-Silva4, \\ Marília Pacífico Lucisano4, Maria Cristina Borsatto5, Paulo Nelson-Filho ${ }^{5}$ \\ DOI: http://dx.doi.org/10.1590/2177-6709.22.2.055-060.oar
}

Objective: The aim of this study was to assess in vitro the influence of the $\mathrm{CO}_{2}$ laser and of the type of ceramic bracket on the shear bond strength (SBS) to enamel. Methods: A total of 60 enamel test surfaces were obtained from bovine incisors and randomly assigned to two groups, according to the ceramic bracket used: Allure (A); Transcend (T). Each group was divided into 2 subgroups ( $\mathrm{n}=15)$ : $\mathrm{L}$, laser (10W, 3s); C, no laser, or control. Twenty-four hours after the bonding protocol using Transbond XT, SBS was tested at a crosshead speed of $0.5 \mathrm{~mm} / \mathrm{min}$ in a universal testing machine. After debonding, the Adhesive Remnant Index (ARI) was evaluated at 10x magnification and compared among the groups. Data were analyzed by one-way ANOVA, Tukey's, Mann-Whitney's and Kruskal-Wallis tests $(\alpha=0.05)$. Results: Mean SBS in MPa were: AL $=0.88 \pm 0.84$; $\mathrm{AC}=12.22 \pm 3.45 ; \mathrm{TL}=12.10 \pm 5.11 ; \mathrm{TC}=17.71 \pm 6.16$. ARI analysis showed that $73 \%$ of the specimens presented the entire adhesive remaining on the tooth surfaces (score 3 ). TC group presented significantly higher SBS than the other groups. The lased specimens showed significantly lower bond strength than the non-lased groups for both tested brackets. Conclusion: $\mathrm{CO}_{2}$ laser irradiation decreased SBS values of the polycrystalline ceramic brackets, mainly Allure.

Keywords: Carbon dioxide. Dental debonding. Lasers. Orthodontic brackets. Shear strength.

Objetivo: o objetivo deste estudo foi avaliar in vitro a influência do laser de $\mathrm{CO}_{2}$ sobre a resistência ao cisalhamento da colagem (RCC) no esmalte dentário, usando diferentes tipos de braquetes cerâmicos. Métodos: no total, 60 superfícies de esmalte de incisivos bovinos foram obtidas e aleatoriamente divididas em dois grupos, de acordo com o braquete cerâmico utilizado: Allure (A) e Transcend (T). Cada grupo foi dividido em dois subgrupos ( $\mathrm{n}=15$ ): L, laser (10W, 3s); C, sem laser, ou controle. Vinte e quatro horas após a colagem dos braquetes com o sistema Transbond XT, foi realizado o teste de resistência ao cisalhamento, com velocidade de 0,5 mm $/ \mathrm{min}$, em máquina universal de ensaios mecânicos. Após a descolagem, o Índice de Remanescente de Adesivo (IRA) foi avaliado com aumento de 10X e comparado entre os grupos. Os dados foram analisados pelo ANOVA one-way, testes de Tukey's, Mann-Whitney's e Kruskal-Wallis $(\alpha=0,05)$. Resultados: as médias da RCC em MPa foram: AL=0,88 $\pm 0,84$; $\mathrm{AC}=12,22 \pm 3,45 ; \mathrm{TL}=12,10 \pm 5,11 ; \mathrm{TC}=17,71 \pm 6,16$. A análise do IRA mostrou que $73 \%$ dos corpos de prova apresentaram todo o compósito remanescente aderido à superficie do esmalte (escore 3). O grupo TC apresentou valor significativamente maior de RCC do que os outros grupos. Os corpos de prova dos grupos com laser obtiveram valores adesivos significativamente menores do que os corpos de prova dos grupos sem laser, com ambos os tipos de braquetes. Conclusão: a irradiação com laser de $\mathrm{CO}_{2}$ diminuiu os valores de RCC dos braquetes policristalinos testados, principalmente do Allure.

Palavras-chave: Dióxido de carbono. Descolagem dentária. Laser. Braquetes ortodônticos. Resistência ao cisalhamento.

${ }^{1}$ Professor, Universidade de São Paulo, Ribeirão Preto Dental School,

Department of Pediatric Clinics, Ribeirão Preto/SP, Brazil.

${ }^{2}$ Dental surgeon, Universidade de São Paulo, Ribeirão Preto Dental School,

Ribeirão Preto/SP, Brazil.

${ }^{3}$ Professor, Universidade Federal dos Vales do Jequitinhonha e Mucuri, School of Biological and Health Sciences, Department of Dentistry, Diamantina/MG, Brazil.

${ }^{4}$ Dental surgeon, Universidade de São Paulo, Ribeirão Preto Dental School, Department of Pediatric Clinics, Ribeirão Preto/SP, Brazil.

${ }^{5}$ Full professor, Universidade de São Paulo, Ribeirão Preto Dental School, Department of Pediatric Clinics, Ribeirão Preto/SP, Brazil.
How to cite this article: Romano FL, Pessoti G, Galo R, Gomes-Silva JM, Lucisano MP, Borsatto MC, Nelson-Filho P. Does the CO2 laser reduce bond strength in different types of ceramic brackets? Dental Press J Orthod. 2017 MarApr;22(2):55-60. DOI: http://dx.doi.org/10.1590/2177-6709.22.2.055-060.oar

Submitted: February 29, 2016 - Revised and accepted: October 14, 2016

» The authors report no commercial, proprietary or financial interest in the products or companies described in this article.

Contact address: Fábio Lourenço Romano

Avenida do Café s/n, Monte Alegre, CEP: 14.040-904

Ribeirão Preto/SP, Brasil - E-mail: fabioromano@forp.usp.br 


\section{INTRODUCTION}

The use of ceramic brackets has become widespread in orthodontic treatments due to the increased number of adult patients seeking care and esthetic appliances. ${ }^{1}$ However, compared to conventional metallic brackets, ceramic brackets are more costly, with a questionable clinical performance, since their rigid properties may cause antagonist tooth contact wear. Also, conventional methods for debonding ceramic brackets (pliers and drills) can cause injuries and fractures to the enamel. ${ }^{2-5}$ The difficulties for debonding ceramic brackets can be attributed to the high bond strength and to the low fracture strength of ceramics, ${ }^{5,6}$ which can lead to iatrogenic enamel damages, bracket fractures and longer clinical chairtime. ${ }^{1-6}$

Therefore, several techniques were suggested for debonding of ceramic brackets, such as electrothermal devices, ${ }^{7}$ ultrasound,${ }^{8}$ solvents ${ }^{9}$ and recently the lasers. ${ }^{5,10-17}$ The use of electrothermal devices has been an effective method in debonding ceramic brackets, however, due to irreversible heating damages to the pulp, this device lost popularity among the clinicians. ${ }^{7}$

The laser debonding technique is based on controlled thermal softening of the adhesive resin that leads to adhesion strength degradation. Studies have shown no pulp damage when debonding brackets with a laser device. . $^{5,10,11,18}$

In this way, despite the good results obtained with different types of lasers, carbon dioxide $\left(\mathrm{CO}_{2}\right)$ laser has been considered the best choice for removing ceramic brackets, due to the high absorption of its wavelength in ceramic surfaces. ${ }^{14,15}$

There are several variables in the studies concerning ceramic bracket removal by lasers, such as: laser settings, type of brackets and bonding agents, as well as the employed methodology. Therefore, in view of the increased use of ceramic brackets in orthodontic patients and the improvements in laser technology and adhesive dentistry in dental practice, the aim of the current investigation was to assess in vitro the influence of $\mathrm{CO}_{2}$ laser use and of the type of ceramic bracket on the shear bond strength (SBS) to enamel. The null hypothesis tested was that the $\mathrm{CO}_{2}$ laser irradiation does not decrease SBS values of the evaluated polycrystalline ceramic brackets.

\section{MATERIAL AND METHODS}

This study had no need to be submitted to an ethics committee in animal experimentation, since the samples were product of commercial slaughter of animal.

Recently extracted sound bovine permanent mandibular incisors were immersed in 0.1\% thymol solution at $4{ }^{\circ} \mathrm{C}$ for 1 week. Prior to use, the teeth were hand scaled, cleaned with pumice-water slurry using Robinson bristle brushes in a low-speed handpiece and examined with a stereomicroscope (Nikon Inc. Instrument Group, Melville, NY, USA) at 10x magnification to discard those with cracks, fractures or structural abnormalities that could interfere in the results. Sixty bovine teeth were selected, thoroughly washed in running water to eliminate storage solution traces, and maintained in distilled water at $4^{\circ} \mathrm{C}$. The samples followed the ISO TR $11405^{19}$ instructions, that recommend 15 teeth per group for shear bond strength tests.

The crowns were embedded in chemically activated acrylic resin (Jet Clássico, São Paulo/SP, Brazil) and after resin polymerization, the buccal enamel surfaces were flattened with \#400- to \#1200-grit silicon carbide (SiC) papers (Buehler Ltd., Lake Bluff, IL, USA) in a low-speed polishing machine (Politriz DP-9U2; Struers, A/S, Copenhagen, Denmark) in order to obtain the test sites that, for standardization, were demarcated by attaching a piece of insulating tape with a central square $(5 \times 5 \mathrm{~mm})$ on each surface. Next, the roots were embedded in chemically activated acrylic resin (Jet Clássico, São Paulo/SP, Brazil) using polyvinyl chloride rings $(2.1 \mathrm{~cm}$ diameter and $1.1 \mathrm{~cm}$ high) in order to facilitate the laser irradiation and the SBS test immediately after.

The 60 enamel test surfaces were randomly assigned to two groups $(n=30)$, according to the used polycrystalline ceramic bracket: A) Allure (GAC, New York, NY, USA), and T) Transcend (3M Unitek, Monrovia, CA, USA).

Prior to the bracket bonding protocol, the test surfaces were cleaned by rubber cup/pumice prophylaxis for $10 \mathrm{~s}$, rinsed and dried for the same time with an oilfree air stream. Next, the enamel surfaces were etched with 37\% phosphoric acid gel (ScotchBond etchant, 3M/ESPE, St. Paul, MN, USA) for $15 \mathrm{~s}$, rinsed thoroughly for $15 \mathrm{~s}$, dried with a mild, oil-free air stream to obtain a uniformly white, opaque, chalk-like appearance. Transbond XT primer (3M Unitek, Monrovia, 
CA, USA) was applied to the acid etched enamel bonding site in a uniform layer, slightly thinned with a mild, oil-free air stream.

The ceramic brackets for lower central incisor were bonded to the center of the specimens using Transbond XT composite (3M Unitek, Monrovia, CA, USA) according to the manufacturer's recommendations. All bonding procedures were performed by the same operator, who used a pair of pliers (Ortoply, Philadelphia, PA, USA), and the excess of material was removed with a sharp explorer (Duflex, Juiz de Fora/MG, Brazil). Each bracket bonding was photoactivated at a $1 \mathrm{~mm}$ distance between the bracket base and the light-curing device for $40 \mathrm{~s}$ (10s for each side of the bracket) with a visible light curing unit (XL 1500; 3M/ESPE, St. Paul, MN, USA) with a $450 \mathrm{~mW} / \mathrm{cm}^{2}$ output power. Light intensity of each device was measured prior to each photo-activation cycle using a curing radiometer (Demetron, Danbury, CT, USA). Then the specimens were randomly divided into two subgroups $(n=15)$ : Laser (L) and No Laser, or control (C). The specimens were stored in distilled water at $37^{\circ} \mathrm{C}$ for $24 \mathrm{~h}$.

Immediately before the SBS test, the samples in the laser group were irradiated. The equipment used for $\mathrm{CO}_{2}$ laser irradiation was a UM-L30 device (ShangaiJue Hua Technology Development Shangai, PR China) emitting at $10.6 \mu \mathrm{m}$ wavelength. The laser beam was delivered in non-contact mode. The laser tip was held perpendicularly at a 4-mm distance from the bracket surface and the light was delivered in focused mode. The parameter settings were $10 \mathrm{~W}$ for 3s. The laser operated at ultra-pulse mode with pulse duration of $100 \mu \mathrm{s}$ (interval time: 0,01s). The time delay between laser irradiation and force application was up to $3 \mathrm{~s}^{17}$.

The SBS was tested to failure using a knife-edge blade in a universal testing machine (Model DL 500, EMIC Ltda., São José dos Pinhais/PR, Brazil) running at a crosshead speed of $0.5 \mathrm{~mm} / \mathrm{min}$ with a 50 kgf load cell (Fig 1).

Mean SBS values (in MPa) and standard deviations were calculated and data were analyzed statistically by one-way ANOVA. Tukey's test was used for multiple comparisons at 5\% significance level.

The debonded specimens were observed with a 10x stereomicroscope (Carl Zeiss, Goettingen, Germany) by an calibrated and experienced examiner, in order to assess the amount of resin material adhered to enamel

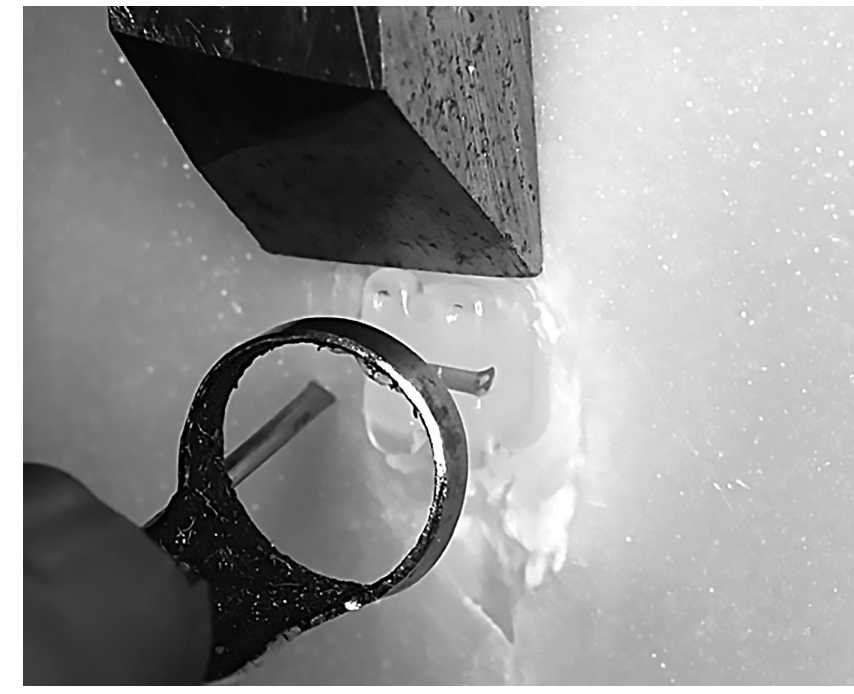

Figure 1 - Specimen with the active chisel tip acting on the upper part of the bracket base during the shear bond strength test.

after bracket removal, which were classified according to the Adhesive Remnant Index (ARI) scores established by Artun and Bergland: ${ }^{20} 0=$ no adhesive remaining adhered to enamel; 1 = less than half of the adhesive remaining adhered to enamel; $2=$ more than half of the adhesive remaining adhered to enamel; $3=$ all the adhesive remaining adhered to enamel. All examinations were done by a single examiner blinded to the groups to which the specimens belonged. The ARI scores data were statistically analyzed by the Kruskal-Wallis test and Mann-Whitney complementary test, at a significance level of $5 \%$.

\section{RESULTS}

SBS means (in MPa), standard deviation, and statistical analysis are presented in Table 1. Group TC presented the highest and group AL present the lowest SBS values of all groups $(p<0.05)$, respectively. There was no statistically significant difference between groups AC and TL. Nevertheless, the SBS values were statistically lower in the $\mathrm{CO}_{2}$ laser irradiated specimens for both Allure and Transcend tested ceramic brackets.

Statistically significant difference $(p<0.05)$ was found in the ARI scores among the four groups. ARI scores are illustrated in Figure 2. According to the results, 73\% of the specimens presented ARI score 3, indicating that bond failure occurred predominantly at the bracket-adhesive interface, leaving most of the adhesive on the enamel surface. ARI score 0 was only observed in one specimen of TL group. 
Table 1 - Comparison of shear bond strength means values (MPa)

\begin{tabular}{cccc}
\hline Groups & n & Mean (SD) & Tukey's test* \\
AC & 15 & $12.22(3.45)$ & $0.88(0.84)$ \\
AL & 15 & b & \\
TC & 15 & c & \\
TL & 15 & $12.10(5.16)$ & \\
\hline
\end{tabular}

* Same letters indicate no statistically significant difference.

$\mathrm{AC}=$ Allure Control; $\mathrm{AL}=$ Allure Laser; $\mathrm{TC}=$ Transcend Control; $\mathrm{TL}=$ Transcend Laser.

Table 2 - Comparison of ARI scores by p values (Mann-Whitney test).

\begin{tabular}{|c|c|c|c|c|}
\hline Groups & $A C$ & $A L$ & $\mathrm{TC}$ & TL \\
\hline$A C$ & --------------- & $0.029 *$ & $0.011^{*}$ & $0.000 *$ \\
\hline $\mathrm{AL}$ & $0.029 *$ & 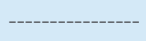 & $0.000 *$ & $0.000 *$ \\
\hline $\mathrm{TC}$ & $0.011^{*}$ & $0.000 *$ & ---------------- & $0.000 *$ \\
\hline $\mathrm{TL}$ & $0.000^{*}$ & $0.000^{*}$ & $0.000^{*}$ & 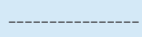 \\
\hline
\end{tabular}

*Changes are significant at $p<0.05$

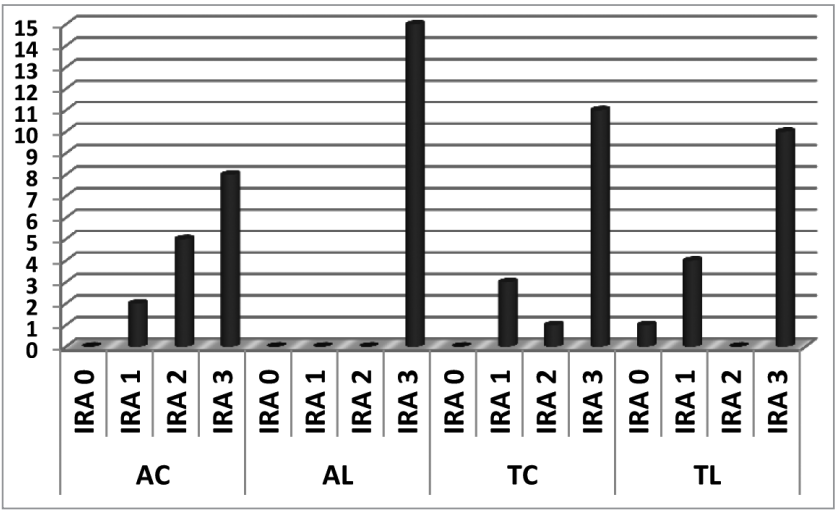

Figure 2 - ARI scores after bracket debonding.

\section{DISCUSSION}

Recently, Orthodontics experienced a great scientific advance regarding the improvement of materials and techniques, allowing more esthetic treatments. Ceramic brackets offer esthetics, durability and better color stability. Nevertheless, enamel cracks and fractures or bracket breakage due to the brittleness, low ductility, high elastic modulus and high adhesion strength to teeth of ceramics have been observed in the conventional debonding of these appliances. ${ }^{1,3}$
According to some authors, laser debonding of ceramic brackets eliminates damages to enamel by reducing the required force to remove it. . $13,14,18,21$ The lasers act softening the adhesive bonding agent by heat conductivity. ${ }^{11,21}$ Saito et al. ${ }^{22}$ concluded that ceramic bracket debonding with $\mathrm{CO}_{2}$ laser, when adhesives containing thermal expansion microcapsules are used, can be an effective and safe method. $\mathrm{CO}_{2}$ laser has been considered the favorite laser device for debonding ceramic brackets since its wavelength is more easily absorbed by these brackets. ${ }^{14,15}$ In the present research, the $\mathrm{CO}_{2}$ laser irradiation decreased the force required to remove the polycrystalline ceramic brackets.

Studies have reported no pulp or enamel tissue injuries and also a decreased debonding force and operation time with $\mathrm{CO}_{2}$ laser. ${ }^{11,15}$ Lijima et al. ${ }^{10}$ have observed that the hardness and elastic modulus of enamel are not affected by $\mathrm{CO}_{2}$ laser irradiation. Nevertheless, the workable laser parameters are directly related to the lasers' ability to soften the adhesive resin without adversely affecting tooth tissues.

The laser settings applied $(10 \mathrm{~W} / 3 \mathrm{~s})$ in this study were based on the findings of a previous investigation done by this research group, in which these $\mathrm{CO}_{2}$ laser parameters did not increase the intrapulpal tempera- 
ture above the pulp physiologic tolerance. ${ }^{17}$ The employed ultra-pulse $\mathrm{CO}_{2}$ laser can provide short pulses with sufficient time to permit tooth tissues to cool down between pulses. ${ }^{15}$ Obata et al..${ }^{11}$ have shown that $\mathrm{CO}_{2}$ laser at $3 \mathrm{~W} / 3 \mathrm{~s}$ are safe settings when debonding brackets, while other authors ${ }^{23}$ reported that $\mathrm{CO}_{2}$ laser irradiation at $50 \mathrm{w}$ for $2 \mathrm{~s}$ increased $0.70^{\circ} \mathrm{C}$ in pulp chamber temperatures. Yassaeiet al..$^{5}$ found a $1.46^{\circ} \mathrm{C}$ increase in intrapulpal temperature after diode laser irradiation at $2.5 \mathrm{~W}$ for $10 \mathrm{~s}$.

As regards as the type of bracket, ceramic brackets are constituted by alumina and are monocrystalline (sapphire) or polycrystalline structures. The monocrystalline ceramic brackets show greater strength, but the fracture resistance is generally below that of the polycrystalline brackets. ${ }^{24,25}$ Also, monocrystalline brackets require lower laser energy for debonding than the polycrystalline brackets ${ }^{21}$ since polycrystalline units do not allow high transmissibility, thus increasing energy loss. ${ }^{26}$ Thus, in the present study, polycrystalline brackets were used and higher values of SBS were observed for the Transcend ceramic brackets, which might be attributed to differences in the base design, structure, and composition of the tested brackets. Perhaps if other laser parameters were used, different SBS values would be reported.

Under clinical conditions, adequate bracket bond strength values might be between 6 to $8 \mathrm{MPa}$ in order to prevent risk of tooth damages at debonding. ${ }^{27}$ However, the force required to remove ceramic brackets can reach values of $20 \mathrm{MPa}$, which might cause tooth or bracket fractures by exceeding the cohesive strength of the enamel or the bracket. ${ }^{2,3,27}$ Confirming these facts, in this study, Transcend ceramic bracket reached a SBS mean of $17.71 \mathrm{MPa}$, which is much higher than the ideal bracket bond strength value.

Additionally, even though the laser decreased the ceramic brackets bond strength, only for the Allure group this reduction (93\%) reached clinically applicable values for debonding (0.88 MPa). The Transcend lased group showed a reduction in $68 \%$, but SBS values $(12.10 \mathrm{MPa})$ were still near the limit of force (11.1 MPa) that can cause tooth fractures at debonding. ${ }^{28}$ In the different treatments (with laser or without laser), the adhesion of Transcend ceramic brackets were higher than Allure. However, significant reduction in the adhesion with both brackets was observed when laser was applied.
Ma et al. ${ }^{18}$ have observed that specimens debonded with $\mathrm{CO}_{2}$ laser $(18 \mathrm{~W} / 2 \mathrm{~s})$ were only $25 \%$ $(1.48 \mathrm{MPa})$ of the mean of the non-lased group. Other authors ${ }^{10}$ reported that $\mathrm{CO}_{2}$ laser irradiated specimens showed a $31 \%$ decrease in SBS, if they were bonded with a conventional etch and rinse adhesive system, and a $25 \%$ decrease with a self-etching adhesive system, compared with control (non-irradiated) specimens. However, these studies tested other materials and techniques.

Concerning ARI scores, the fractures after bracket debonding occurred predominantly at the bracket/ resin interface (73\%, score 3$)$, which reduces the risk of bracket or tooth damages. ${ }^{29}$ ARI scores 1 and 2 occurred as the SBS increased and score 0 was observed only in one TL group specimen, situation in which cracking of the enamel is more probable. ${ }^{28}$ These findings suggest that, in addition to softening, the adhesive resin might have undergone thermal ablation and photoablation, resulting in vaporization and decomposition of the material. ${ }^{1}$ The high percentage of score 3 (all composite remain after debonding) indicated that laser irradiation didn't cause injuries or fractures in the enamel surface, preserving the dental structure (Fig 2). In groups 1, 3 and 4, this score was predominant and in group 2, all sample obtained this same result. These results are promising, and probably during laser irradiation procedure a slight softening of the composite occurred, without heating the tooth.

In view of the above considerations and based on findings of the current investigation, the $\mathrm{CO}_{2}$ laser has been noted as a promising technology in debonding ceramic brackets, mainly for the Allure, since it was observed a greater adhesive remnant index on the tooth surface together with decreased SBS values.

There is still much to be investigated concerning specific laser parameters for the adhesive resins and ceramic brackets available for orthodontic treatment, in order to justify the use of such protocols in clinical orthodontic practice. As regards time saving, lower complexity of treatment, decreased damages to tooth structures and discomfort, the use of lasers for debonding esthetic ceramic brackets has a significant advantage over the traditional method. The lack of reported studies testing the same methodology and materials used in the present study did not allow a reliable comparison with the outcomes of previous researches. 


\section{CONCLUSION}

The null hypothesis was rejected. The $\mathrm{CO}_{2}$ laser irradiation decreased the adhesion of the ceramic brackets and enhanced brackets debonding.

\section{Acknowledgements}

The authors would like to thank the National Council for Research - CNPq (\#11.1.754.58.0) for the research grant and financial support.

\section{Authors contribution}

Conception or design of the study: FLR, MCB, PNF. Data acquisition, analysis or interpretation: GP, MPL, RG. Writing the article: FLR, JMGS. Critical revision of the article: FLR, PNF. Final approval of the article: FLR. Obtained funding: GP.
1. Azzeh E, Feldon PJ. Laser debonding of ceramic brackets: a comprehensive review. Am J Orthod Dentofacial Orthop. 2003 Jan;123(1):79-83.

2. Jena AK, Duggal R, Mehrotra AK. Physical properties and clinical characteristics of ceramic brackets: a comprehensive review. Trends Biomater Artif Organs. 2007:20:201-19.

3. Jeiroudi MT. Enamel fracture caused by ceramic brackets. Am J Orthod Dentofacial Orthop. 1991 Feb;99(2):97-9.

4. Bishara SE, Fonseca JM, Boyer DB. The use of debonding pliers in the removal of ceramic brackets: force levels and enamel cracks. Am J Orthod Dentofacial Orthop. 1995 Sept:108(3):242-8.

5. Yassaei S, Soleimanian A, Nik ZE. Effects of diode laser debonding of ceramic brackets on enamel surface and pulpal temperature. J Contemp Dent Pract. 2015 Apr 1;16(4):270-4

6. Scott GE Jr. Fracture toughness and surface cracks--the key to understanding ceramic brackets. Angle Orthod. 1988 Jan;58(1):5-8

7. Dovgan JS, Walton RE, Bishara SE. Electrothermal debracketing: patient acceptance and effects on the dental pulp. Am J Orthod Dentofacial Orthop. 1995 Sept:108(3):249-55.

8. Boyer DB, Engelhardt G, Bishara SE. Debonding orthodontic ceramic brackets by ultrasonic instrumentation. Am J Orthod Dentofacial Orthop. 1995 Sept;108(3):262-6

9. Larmour CJ, McCabe JF, Gordon PH. An ex vivo investigation into the effects of chemical solvents on the debond behaviour of ceramic orthodontic brackets. $\mathrm{Br}$ J Orthod. 1998 Feb;25(1):35-9.

10. lijima M, Yasuda Y, Muguruma T, Mizoguchi I. Effects of $C O(2)$ laser debonding of a ceramic bracket on the mechanical properties of enamel. Angle Orthod. 2010 Nov:80(6):1029-35

11. Obata A, Tsumura T, Niwa K, Ashizawa Y, Deguchi T, Ito M. Super pulse CO2 laser for bracket bonding and debonding. Eur J Orthod. 1999 Apr;21(2):193-8.

12. Sarp AS, Gülsoy M. Ceramic bracket debonding with ytterbium fiber laser. Lasers Med Sci. 2011 Sept;26(5):577-84.

13. Oztoprak MO, Nalbantgil D, Erdem AS, Tozlu M, Arun T. Debonding of ceramic brackets by a new scanning laser method. Am J Orthod Dentofacial Orthop. 2010 Aug:138(2):195-200.

14. Tehranchi A, Fekrazad R, Zafar M, Eslami B, Kalhori KA, Gutknecht N. Evaluation of the effects of $\mathrm{CO} 2$ laser on debonding of orthodontics porcelain brackets vs. the conventional method. Lasers Med Sci. 2011 Sept;26(5):563-7.

15. Ahrari F, Heravi F, Fekrazad R, Farzanegan F, Nakhaei S. Does ultra-pulse CO(2) laser reduce the risk of enamel damage during debonding of ceramic brackets? Lasers Med Sci. 2012 May;27(3):567-74.
16. Tozlu M, Ostoprak MO, Arun T. Comparison of shear bond strengths of ceramic brackets aftediferente times lags between lasing and debonding. Lasers Med Sci. 2012 Nov:27(6):1151-5.

17. Macri RT, Lima FA, Bachmann L, Galo R, Romano FL, Borsatto MC, et al. CO2 laser as auxiliary in the debonding of ceramic brackets. Lasers Med Sci. 2015 Sept;30(7):1835-41

18. Ma T, Marangoni RD, Flint W. In vitro comparison of debonding force and intrapulpal temperature changes during ceramic orthodontic bracket removal using a carbon dioxide laser. Am J Orthod Dentofacial Orthop. 1997 Feb;111(2):203-10.

19. International Organization for Standardization. Guidance on testing of adhesion to tooth structure. ISSO/TC106/SC 1 N236, Resolution 61. CD TR 11405, Trieste, Oct 1994.

20. Artun J, Bergland S. Clinical trials with crystal growth conditioning as an alternative to acid-etch enamel pretreatment. Am J Orthod. 1984 Apr;85(4):33340 .

21. Strobl K, Bahns TL, Willham L, Bishara SE, Stwalley WC. Laser-aided debonding of orthodontic ceramic brackets. Am J Orthod Dentofacial Orthop. 1992 Feb;101(2):152-8

22. Saito A, Namura Y, Isokawa K, Shimizu N. CO2 laser debonding of a ceramic bracket bonded with orthodontic adhesive containing thermal expansion microcapsules. Lasers Med Sci. 2015 Feb;30(2):869-74.

23. Abdul-Kader HM, Ibrahim AS. A comparative study of $\mathrm{CO} 2$ laser debonding of three types of ceramic brackets. J Dent Sci. 1999;2:79-84.

24. Mimura H, Deguchi T, Obata A, Yamagishi T, Ito M. Comparison of different bonding materials for laser debonding. Am J Orthod Dentofacial Orthop. 1995 Sept;108(3):267-73

25. Flores DA, Caruso JM, Scott GE, Jeiroudi MT. The fracture strength of ceramic brackets: a comparative study. Angle Orthod. 1990 Winter;60(4):269-76.

26. Eliades T, Johnston WM, Eliades G. Direct light transmittance through ceramic brackets. Am J Orthod Dentofacial Orthop. 1995 Jan;107(1):11-9.

27. Reynolds I. A review of direct orthodontic bonding. Br J Orthod. 1975;2(3):71-8.

28. Bishara SE, Fehr DE, Jakobsen JR. A comparative study of the debonding strengths of different ceramic brackets, enamel conditioners, and adhesives. Am J Orthod Dentofacial Orthop. 1993 Aug;104(2):170-9.

29. Nalbantgil D, Oztoprak MO, Tozlu M, Arun T. Effects of different application durations of ER:YAG laser on intrapulpal temperature change during debonding Lasers Med Sci. 2011 Nov:26(6):735-40. 